\title{
KUNCI KEAMANAN DAN PEMBATAS KECEPATAN UNTUK SEPEDA MOTOR MENGGUNAKAN SENSOR KECEPATAN BERBASIS MIKROKONTROLLER
}

\section{SECURITY KEY AND SPEED LIMITER FOR MOTORCYCLE USING SPEED SENSOR BASED ON MICROCONTROLLER}

\author{
Tomy Okta Syafri Yando ${ }^{1}$, Roby Rifaldy \\ Hartanto $^{2}$, Tody Ariefianto Wibowo ${ }^{3}$, Dwi Andi \\ Nurmantris ${ }^{4}$ \\ 1,2,4Prodi D3 Teknik Telekomunikasi, Fakultas Ilmu \\ Terapan, Universitas Telkom \\ ${ }^{2}$ Prodi S1 Teknik Elektro, Fakultas Teknik Elektro, Universitas Telkom \\ 1tomiokta@yahoo.com.au, ${ }^{2}$ Roby.kjn@gmail.com, ${ }^{3}$ tody.wibowo@gmail.com, \\ ${ }^{4}$ dwiandi@tass.telkomuniversity.ac.id
}

\begin{abstract}
Abstrak
Pada saat ini, sepeda motor telah menjadi kebutuhan utama bagi warga masyarakat sebagai alat pendukung aktivitas sehari-hari. Model yang semakin bervariasi dan harganya yang semakin kompetitif membuat populasi sepeda motor juga makin meningkat. Sayangnya, makin menjamurnya sepeda motor, makin meningkat juga kasus-kasus pencurian sepeda motor. Di sisi lain, resiko cidera bahkan kematian makin mengancam para pengguna sepeda motor sendiri dengan banyaknya kasus-kasus kecelakaan yang melibatkan sepeda motor. Pada penelitian ini, kami merancang dan mengimplementasikan kunci keamanan pada sepeda motor untuk mengurangi resiko pencurian serta pembatas kecepatan untuk mengurangi resiko kecelakaan bagi pengguna sepeda motor. Kedua fungsi alat ini dirancang menggunakan sensor kecepatan dan mikrokontroller ATmega328 atau dikenal Arduio Uno. Diharapkan alat ini bisa bermanfaat buat warga masyarakat terutama para pengguna sepeda motor.
\end{abstract}

Kata kunci : Sensor kecepatan, Mikrokontroler, Kunci Keamanan, Pembatas Kecepatan

\section{Abstract}

Today, motorcycle has become a major requirement for the citizens as a tool to support daily activities. Models are increasingly varied and increasingly competitive price make the motorcycle population is also increasing. Unfortunately, the increasing of motorcycles, increasing also cases of motorcycle theft. On the other hand, the risk of injury and even death increasingly threatening motorcycle users themselves with the many cases of accidents involving motorcycles. In this study, we design and implement a security lock on the motorcycle to reduce the risk of theft as well as limiting the speed of motorcycle to reduce the risk of accidents for motorcyclists. Both function of the tool is designed using the speed sensor and microcontroller ATmega328 or known as Arduio Uno. Hopefully, this tool can be useful for citizens, especially for the users of motorcycles.

Keywords : Speed Sensor, Microcontroller, Security Key, Speed Limiter.

\section{PENDAHULUAN}

Sepeda motor saat ini menjadi kebutuhan masyarakat dari kalangan bawah sampai kalangan atas. Keberadaannya sangat membantu masyarakat dalam menjalankan aktivitas seharihari yang menuntut masyarakat bergerak dengan cepat. Sepeda motor menjadi pilihan utama untuk transportasi masyarakat pada saat ini karena bisa menembus jalanan yang sekarang sudah mulai padat dimana penggunaan kendaraan roda empat nyaris tidak menjadi pilihan. Selain itu, variasi sepeda motor yang semakin beragam serta harganya yang relatif terjangkau menjadi faktor tingginya minat masyarakat akan sepeda motor. 
Sayangnya, tingginya penggunaan sepeda motor ini juga mengakibatkan potensi tindak kejahatan pencurian sepeda motor juga semakin besar. Sudah sering terjadi kejadian pembobolan sepeda motor yang terjadi pada bagian kontak motor di daerah yang kurang aman atau karena kecerobohan pemilik kendaraan yang meningalkan sepeda motornya dalam keadaan hidup. Hampir tiap hari berita-berita kriminal tidak absen memberitakan aksi-aksi pencurian sepeda motor tersebut.

Disisi lain, ancaman akan kecelakaan berkendara terutama bagi para pengendara sepeda motor makin tinggi. Dalam dua tahun terakhir ini, kecelakaan lalu lintas di Indonesia oleh World Health Organization/Badan Kesehatan Dunia (WHO) dinilai menjadi pembunuh terbesar ketiga, di bawah penyakit jantung koroner dan tuberculosis/TBC. Data WHO tahun 2011 menyebutkan, sebanyak 67 persen korban kecelakaan lalu lintas berada pada usia produktif , yakni 22 - 50 tahun. Terdapat sekitar 400.000 korban di bawah usia 25 tahun yang meninggal di jalan raya, dengan rata-rata angka kematian 1.000 anak-anak dan remaja setiap harinya. Bahkan, kecelakaan lalu lintas menjadi penyebab utama kematian anak-anak di dunia, dengan rentang usia 10-24 tahun. Data Kepolisian RI menyebutkan, pada 2012 terjadi 109.038 kasus kecelakaan dengan korban meninggal dunia sebanyak 27.441 orang, dengan potensi kerugian sosial ekonomi sekitar Rp 203 triliun - Rp 217 triliun per tahun (2,9\% - 3,1 \% dari Pendapatan Domestik Bruto/PDB Indonesia). Sedangkan pada 2011, terjadi kecelakaan sebanyak 109.776 kasus, dengan korban meninggal sebanyak 31.185 orang [3].

Ada empat faktor utama yang menyebabkan terjadikanya kecelakaan, pertama adalah faktor manusia, kedua adalah faktor kendaraan, ketiga adalah faktor jalan, dan keempat adalah faktor lingkungan. Kombinasi dari keempat faktor itu bisa saja terjadi, antara manusia dengan kendaraan misalnya adalah mengendarai sepeda motor melebihi batas kecepatan yang ditetapkan kemudian ban pecah yang mengakibatkan terjadi kecelakaan.

Resiko pencurian dan kecelakaan pada para pemakai sepeda motor tersebut adalah ancaman serius yang membutuhkan perhatian khusus dari berbagai pihak yaitu dari pengguna sendiri, produsen sepeda motor, pemerintah, bahkan aparat kepolisian. Para pengguna diharapkan akan kesadarannya untuk tertib berlalu lintas. Sedangkan produsen sepeda motor diharapkan meningkatkan sistem keamanan akan sepeda motor yang diproduksinya.

Sebagai wujud partisipasi dalam upaya mengurangi resiko pencurian dan kecelakaan tersebut, beberapa penelitian tentang keamanan sepeda motor telah dilakukan. Diantara penelitianpenelitian tersebut adalah dengan dibuatnya sistem keamanan motor berbasis mikrokontroller Atmega8535 dengan mengimplementasikan sensor ultrasonik, sensor getaran dan modem Wavecom Fastrack M1306B untuk mengirimkan peringatan melalui SMS [1], selain itu dibuat juga sistem keamanan sepeda motor berbasis mikrokontroller AT89C51 dengan mengimplementasikan sensor ultrasonik dan rangkaian pengaman kunci [4], dibuat juga sistem keamanan motor berbasiskan mikrokontroller AVR ATMega8535 dengan mengimplementasikan telepon seluler agar bisa berkomunikasi dua arah antara motor dengan pemiliknya [7]. Pada penelitian ini, direalisasikan suatu alat yang dapat membantu meningkatkan keamanan pada sepeda motor dengan menggunakan keypad berupa masukan pin kode sesuai dengan yang telah diset. Selain itu terdapat sensor kecepatan yang dapat membantu keamanan sepeda motor pada saat ditinggalkan dalam keadaan motor hidup ataupun mati. Selain itu juga, sensor kecepatan tersebut juga kami gunakan untuk membatasi kecepatan sepeda motor untuk mengurangi faktor-faktor penyebab kecelakaan. Alat yang berbasis mikrokontroller ATmega328 atau dikenal Arduio Uno ini diharapkan bisa menjadi salah satu solusi akan permasalahan yang kami kemukakan diawal. 


\section{PERANCANGAN SISTEM KEAMANAN SEPEDA MOTOR}

Sistem keamanan pada sepeda motor yang kami rancang ini memiliki 2 fitur utama yaitu pertama : kunci keamanan dan sistem alarm yang fungsinya untuk mengakses penggunaan sepeda motor serta memeri peringatan baik bagi pemilik sepeda motor atau orang lain yang berniat ingin mencuri, dan kedua : pembatas kecepatan (Speed Limiter) yang fungsinya untuk membatasi kecepatan yang dapat dicapai oleh pengguna sepeda motor. Pada fitur pertama, kunci keamanan dirancang menggunakan keypad dimana kesalahan pemasukan kode sebanyak 3 kali akan memicu alat untuk membunyikan alarm yang telah diintegrasikan juga dalam alat ini. Selain alarm akan berbunyi ketika kesalahan pemasukan kode kunci, alarm juga akan berbunyi ketika sepeda motor bergerak sejauh 24 meter /15 putaran roda motor dalam keadaan mati atau hidup dengan menggunakan bantuan sensor kecepatan. Fitur yang kedua masih memanfaatkan sensor kecepatan untuk menghitung kecepatan sepeda motor sehingga apabila telah melampaui batas yang telah ditetapkan alarm akan berbunyi selama 15 detik. Ketika alarm tidak diindahkan maka sistem akan memutuskan arus pada motor untuk menurunkan kecepatan motor secara paksa selama 10 detik. Ketika kecepatan sudah dibawah batas, mesin motor akan hidup kembali.

\subsection{Spesifikasi Alat}

Secara umum sistem keamanan sepeda motor yang kami rancang memiliki spesifikasi sebagai berikut :

- Catu daya atau aki memiliki tegangan $12 \mathrm{~V}$ dan arus listrik sebesar $3 \mathrm{~A}$

- Keluaran alarm sebesar 25dB

- Alarm akan berbunyi ketika sepeda motor menempuh jarak $\geq 24$ m pada saat sepeda motor dalam keadaan mati ataupun menyala yang bergerak tanpa memasukan password terlebih dahulu.

- Mendukung sistem penggantian password

- Maksimal kesalahan input password sebanyak 3 kali

- Mendukung input perubahan batas kecepatan pada saat menggunakan fitur speed limiter

- Dimensi alat $20 \times 15 \mathrm{~cm}$

\subsection{Perancangan Hardware}

Sistem keamanan pada sepeda motor yang kami rancang ini menggunakan beberapa hardware diantaranya adalah sebuah Mikrokontroler ATmega 328 (Arduino Uno), Keypad, Sensor kecepatan (SD-536A), Alarm, dan LCD. Sedangkan catudaya untuk alat ini diambil dari aki motor. Blok diagram hardware sistem keamanan bisa dilihat pada Gambar 1 .

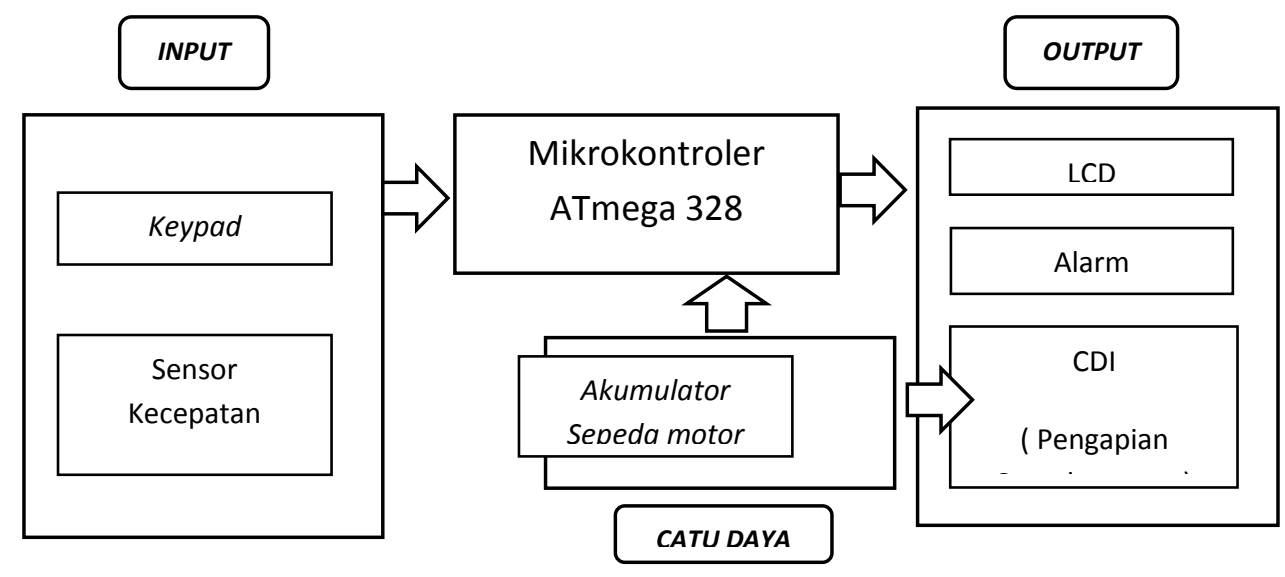

Gambar 1. Blok Diagram Hardware Sistem Keamanan Sepeda Motor 


\subsubsection{Blok Input}

Blok ini terdiri dari Keypad dan Sensor kecepatan. Keypad berfungsi sebagai tombol untuk input password, perubahan password, dan input batas kecepatan. Lalu sensor kecepatan ditempelkan pada roda sepeda motor untuk membaca berapa banyak putaran yang terjadi pada roda. Sensor kecepatan ini merupakan komponen paling penting pada sistem keamanan fitur sistem alarm dan fitur speed limiter.

\section{Keypad $[8]$}

Pada perancangan alat ini, input pin data menggunakan keypad $3 \times 4$ yang terdiri dari 12 tombol (3 kolom dan 4 baris). Metode yang digunakan adalah metode scanning, dimana tiap pin nantinya akan diberi logika " 0 " atau "1" untuk memunculkan angka yang diinginkan. Berikut gambar dari keypad 3x4 yang digunakan.

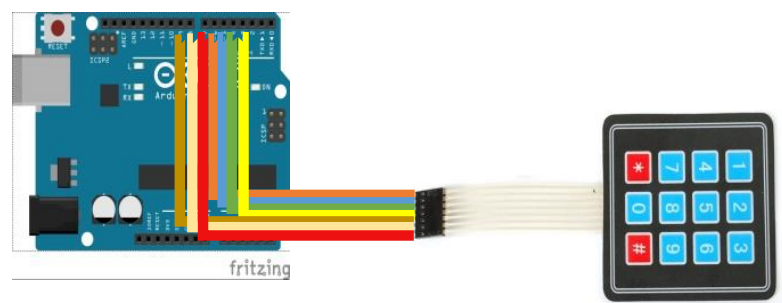

Gambar 2. Perancangan Keypad 3x4

PIN output dari keypad dihuungkan langsung dengan pin yang ada pada Arduino. Pin yang digunakan untuk mengkoneksikan keypad dengan Arduino Uno adalah pin 9, 8, dan 7 untuk kolom pada keypad sedangkan pin 6, 5, 4 dan 3 untuk baris pada keypad. Pada saat salah satu tombol pada keypad ditekan, Arduino memproses data yang dikeluarkan oleh keypad dan mengkonversi data tersebut menjadi karakter angka yang ditekan. Angka tersebut akan muncul pada layar LCD. Tombol "\#” pada keypad berfungsi untuk mengganti batas kecepatan pada sepeda motor.

\section{Sensor Kecepatan [6]}

Sensor kecepatan dengan reed switch sangat simpel dan mudah diaplikasikan. Reed swtich merupakan sebuah saklar yang terbuat dari 2 plat besi. Switch tersebut akan tertutup (short circuit) apabila didekatkan dengan magnet.

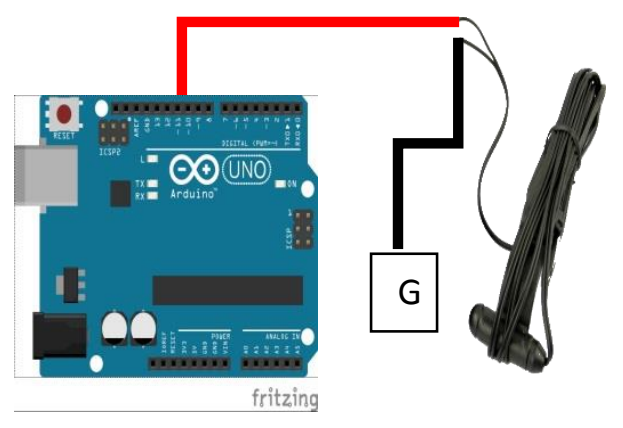

Gambar 3. Perancangan Sensor Kecepatan

Ketika reed switch tertutup maka arduino uno akan menerima inputan berupa pulsa. reed switch ditempatkan pada bagian as roda depan sepeda motor, sedangkan magnet ditempatkan pada bagian jari-jari sepeda motor, untuk sistem keamanan pada saat sepda motor menyala ataupun mati.sensor kecepatan akan membaca berapa banyak putaran roda (jumlah pulsa) pada sepeda motor, jika putaran roda melebihi batasan yang sudah ditentukan maka sistem keamanan akan hidup. 


\subsubsection{Blok Output}

Blok ini terdiri dari LCD, Alarm, dan Relay \& CDI. Alarm berfungsi sebagai output untuk memberikan peringatan berupa suara. LCD berfungsi sebagai penampil karakter angka atau huruf sesuai sistem alat yang digunakan. CDI berfungsi sebagai sistem pengapian pada speda motor. Pada CDI terdapat relay yang berfungsi untuk memutuskan arus listrik.

\section{LCD 2x16 [5]}

Display yang digunakan dalam sistem ini adalah LCD $2 \times 16$. LCD disini berperan sebagai output dan berfungsi sebagai penampil karakter angka. Password dan batas kecepatan yang diinput pada keypad akan ditampilkan pada layar LCD tersebut, untuk memastikan apakah password dan batas kecepatan yang telah di input sesuai atau tidak.

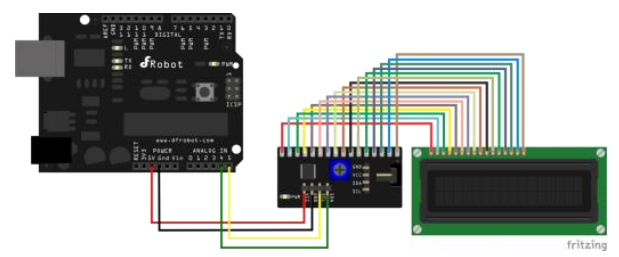

Gambar 4. Perancangan LCD 2x16

LCD sendiri membutuhkan tegangan aktif sebesar 5volt. pada LCD terdapat banyak kakikaki yang harus disambungkan ke Arduino Uno seperti pin data, pin RS, pin R/W, pin E, dan pin VLCD agar bisa saling berkomunikasi. Pada perancangan yang dibuat, kaki-kaki LCD yang terhubung langsung dengan pin yang ada pada Arduino Uno yaitu pin A5 dan A4 sesuai dengan gambar perancangan diatas.

\section{$\underline{\text { Alarm }}$}

Dalam sistem perancangan alat ini, sebuah alat yang digunakan adalah Alarm 12V. Alarm berfungsi sebagai tanda peringatan. PIN digital 11 pada Arduino uno digunakan sebagai port output untuk mengaktifkan alarm. Catuan alarm 12 Volt berasal dari Akumulator

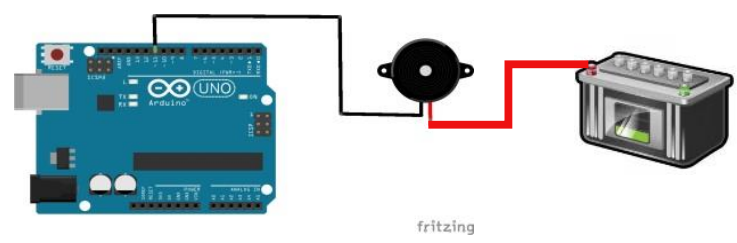

Gambar 5. Perancangan Sistem Alarm

\section{$\underline{\text { Relay dan CDI }}$}

Relay adalah suatu rangkaian switching magnetik yang bekerja bila lilitan internal diberi arus listrik. Relay memiliki tegangan dan arus nominal yang harus dipenuhi output rangkaian pengemudinya. Arus yang digunakan pada rangkaian adalah arus DC. Relay berfungsi untuk mengaktifkan sistem keamanan ketika password yang dimasukan salah dan sebagai pemutus arus untuk menurunkan kecepatan pada sepeda motor, jika batas kecepatan pada sepeda motor melebihi batas yang ditentukan. Ketika sepeda motor sudah menyala dan mencoba menjalankan sepeda motor tanpa memasukan password atau memasukan password yang tidak sesuai maka arus yang mengalir pada CDI ke COIL akan terputus dan sepeda motor akan mati. Rangkaian relay dan CDI bisa dilihat pada Gambar 6 . 


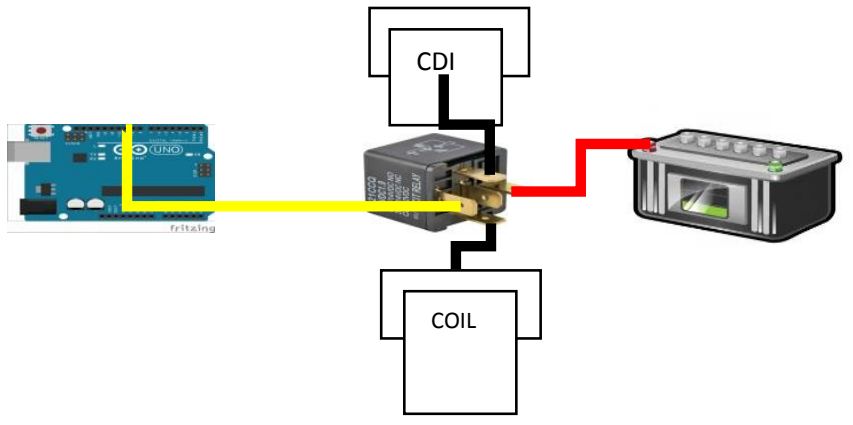

Gambar 6. Perancangan Relay dan CDI

\subsubsection{Mikrokontroler Atmega 328 (Arduino Uno)[2]}

Arduino UNO adalah sebuah board mikrokontroler ATMega328. Arduino UNO mempunyai 14 pin digital input/output (6 di antaranya dapat digunakan sebagai output PWM), 6 input analog, sebuah osilator Kristal $16 \mathrm{MHz}$, sebuah koneksi USB, sebuah power jack, sebuah ICSP header. Arduino Uno dapat dihubungkan ke komputer melalui kabel USB. Spesifikasi Arduino Uno yang digunakan adalah sebagai berikut :

Mikrokontroler

Operating Voltage

Input Voltage (disarankan)

Input Voltage (batas)

Digital I/O

Analog Input

DC Current per I/O

DC Current for 3.3V

Flash Memory 32KB (ATMega328)

SRAM

EEPROM

Clock Speed
: ATMega328

$: 5 \mathrm{~V}$

$: 7-12 \mathrm{~V}$

$: 6-20 \mathrm{~V}$

: 14 Pins (6 dapat difungsikan sebagai output PWM)

: 6 Pins

: Pin $40 \mathrm{~mA}$

: Pin $50 \mathrm{~mA}$

: $0.5 \mathrm{~KB}$ digunakan oleh bootloader

: 2 KB (ATMega328)

: $1 \mathrm{~KB}$ (ATMega328)

: $16 \mathrm{MHz}$

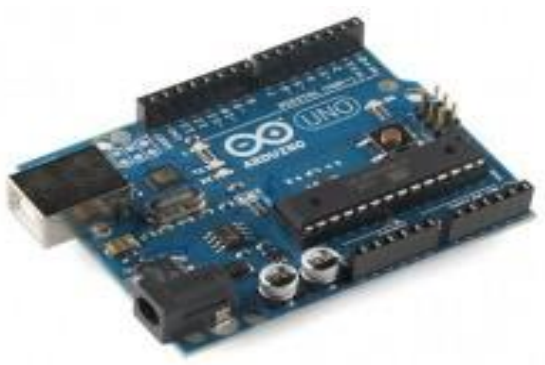

Gambar 7. Arduino UNO[2]

\subsection{Perancangan Software}

Perancangan software pada alat ini menggunakan software Arduino IDE. Arduino IDE merupakan penggabungan antara bahasa $\mathrm{C}++$ dan Java. Software ini dapat diinstall dalam berbagai operating system (OS) seperti, LINUX, Mac dan Windows.

Struktur perintah pada arduino secara garis besar terdiri dari dua bagian, yaitu void setup dan void loop. Void setup berisi perintah yang akan dieksekusi satu kali sejak arduino dihidupkan. Sedangkan void loop berisi perintah yang akan dieksekusi secara berulang-ulang selama arduino dinyalakan. 


\subsubsection{Logika Program Pengaksesan Sepeda Motor}

Sistem keamanan kendaraan sepeda motor ini dirancang untuk dapat bekerja pada kondisi mesin motor dalam keadaan mati maupun hidup, dalam kondisi motor digunakan maupun tidak. Flowchart pengaksesan sepeda motor dapat dilihat pada Gambar 8.

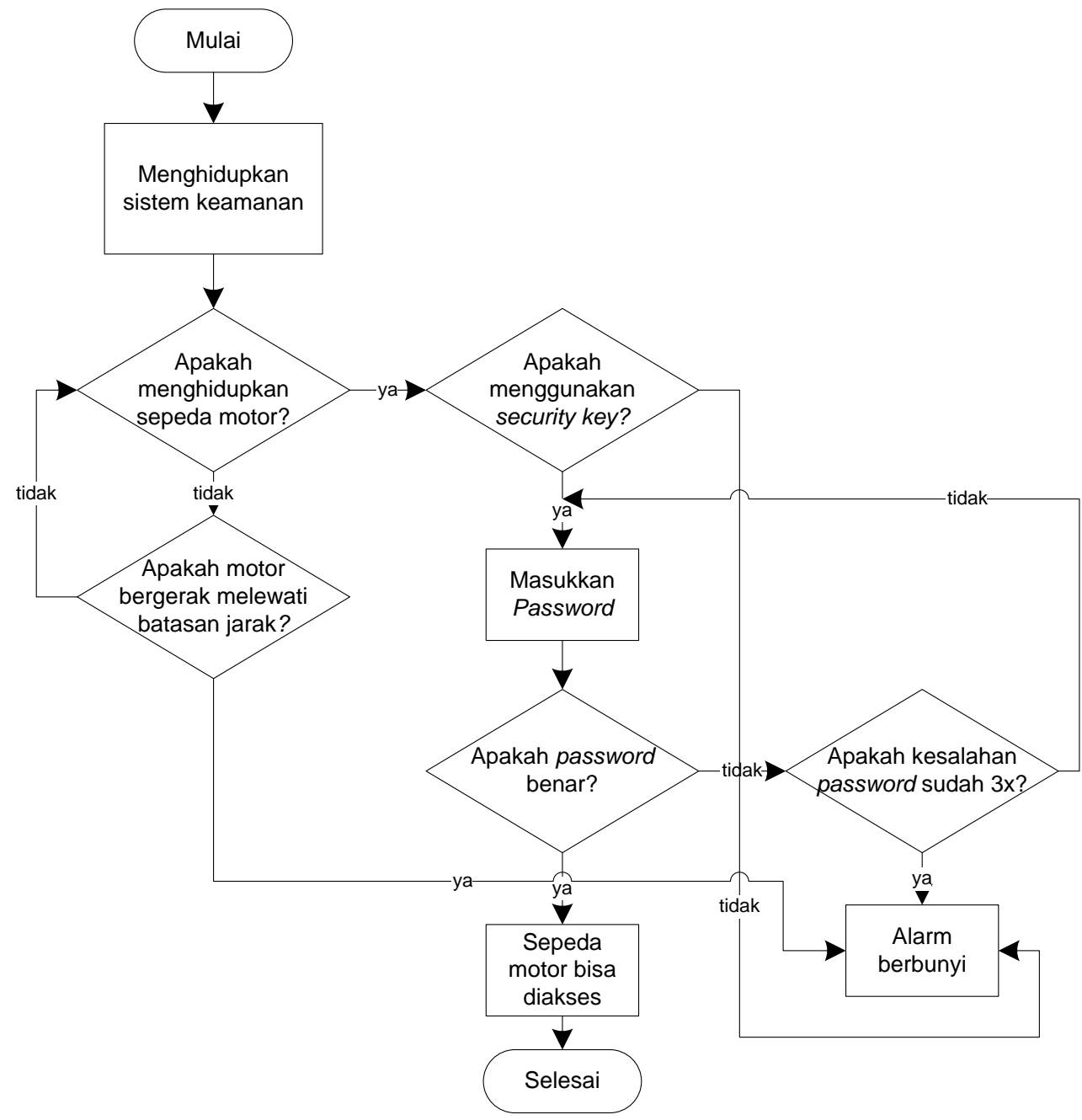

Gambar 8. Flowchart Pengaksesan Sepeda Motor

\subsubsection{Logika Program Penggantian Password}

Algoritma penggantian password pada kunci keamanan perlu dirancang agar password dapat diganti sesuai keinginan pengguna. Flowchart penggantian password bisa dilihat pada gambar 9.

\subsubsection{Algoritma Program Speed Limiter}

Salah satu fitur penting pada alat ini bagi para pengguna sepeda motor adalah pembatas kecepatan (speed limiter). Algotitma pembatas kecepatan berfungsi untuk mengatur batas kecepatan maksimum. Alat akan memberi tanda peringatan jika pengendara telah melampaui kecepatan maksimal. Flowchart pembatas kecepatan bisa dilihat pada gambar 10. 


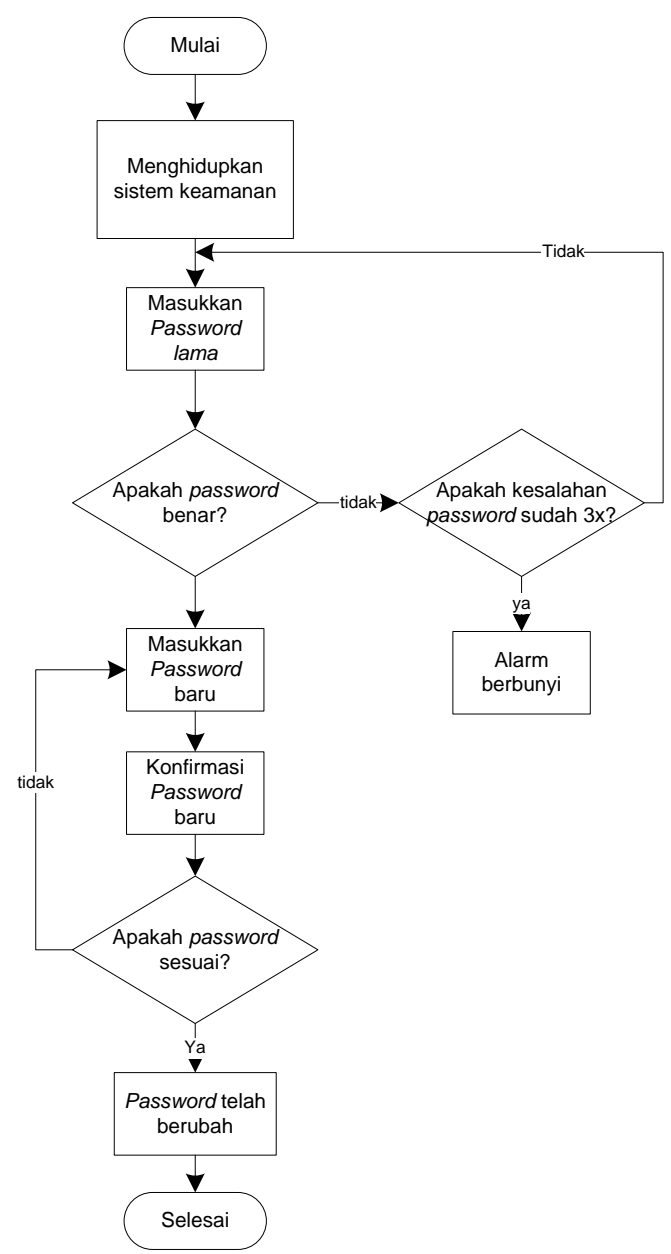

Gambar 9. Flowchart Penggantian Password

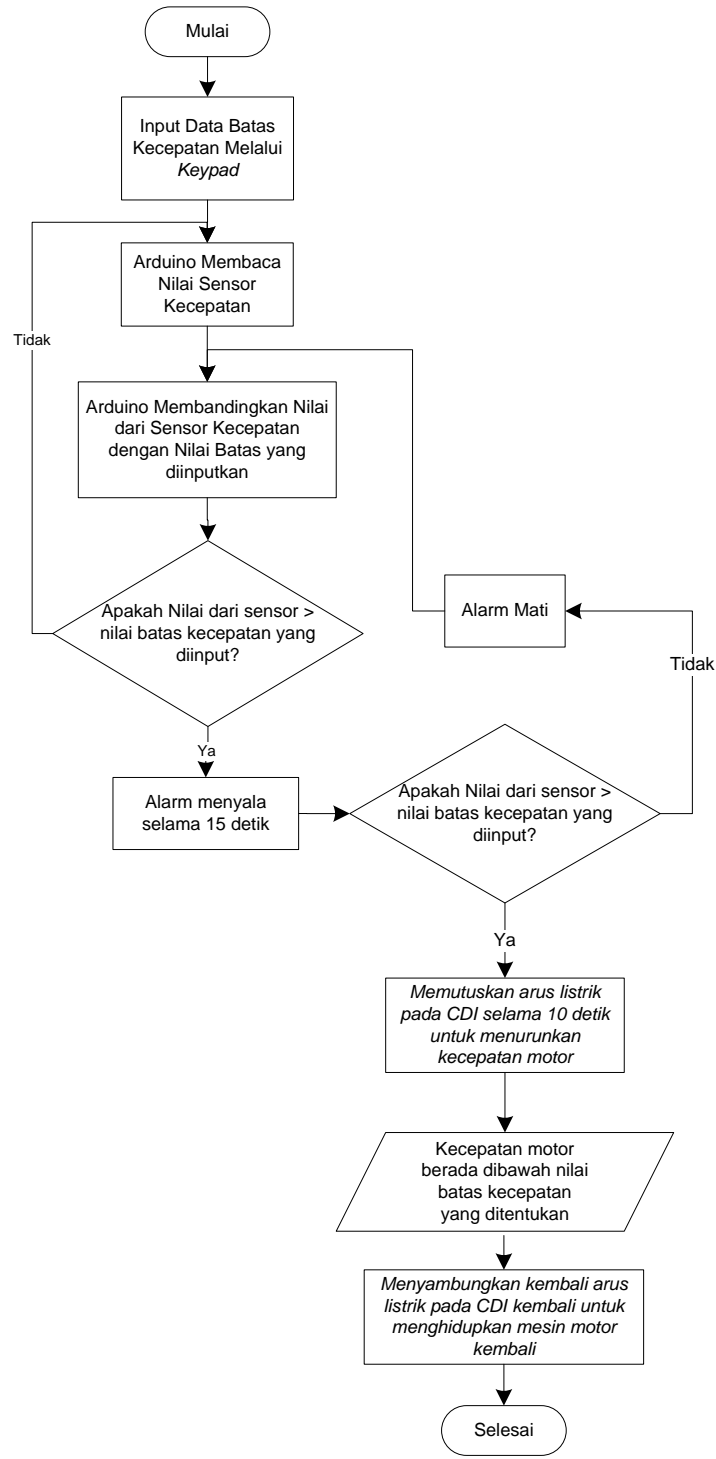

Gambar 10. Flowchart untuk Speed Limiter

\section{Pengujian Alat dan Pembahasan}

Pada bab ini dijelaskan hasil pengujian dari realisasi sistem yang telah dirancang. Dari parameter-parameter hasil pengujian akan diketahui sejauh mana kinerja alat ini.

\subsection{Pengujian Kunci Keamanan}

Pengujian ini dilakukan pada keypad, LCD, dan Arduino Uno untuk memastikan kunci keamanan berjalan dengan baik. Keypad berfungsi untuk memasukan angka yang berupa password yang nantinya akan ditampilkan pada serial monitor atau LCD. Pin yang digunakan untuk menghubungkan keypad dengan Arduino Uno adalah pin 9, 8, dan 7 untuk kolom pada keypad sedangkan pin 6, 5, 4 dan 3 untuk baris pada keypad. Jika password yang dimasukan pada keypad benar maka akan muncul tulisan "PIN oke". Sedangkan jikas password yang dimasukan pada keypad salah maka akan muncul tulisan "PIN error". Password juga dapat diganti sesuai denggan yang diinginkan denggan cara memasukan terlebih dahulu password lama sebelum mengganti denggan yang baru. Contoh tampilan pengujian password benar bisa dilihat pada gambar 11a. 
Dengan menekan enam digit angka yang sudah ditentukan sistem keamanan akan dimatikan dan sepeda motor dapat digunakan. Penggantian password juga dapat dilakukan setelah memasukan password lama terlebih dahulu dan menekan pagar untuk mengganti password. Password lama sudah tergganti jika sudah terlihat seperti pada gambar 11b. Penggantian password dapat dilakukan saat keadaan sepeda motor sedang menyala, setelah melakukan pengantian password matikan terlebih dahulu sepeda motor untuk menggunakan password yang bar

"Pin error" akan muncul pada LCD seperti pada gambar 11c ketika password yang dimasukan salah. Setelah password salah sebanyak tiga kali berturut-turut maka alarm berbunyi.

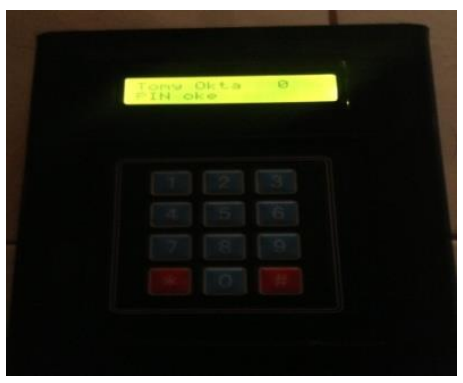

(a)

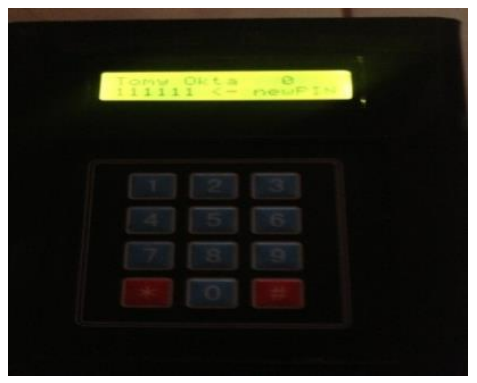

(b)

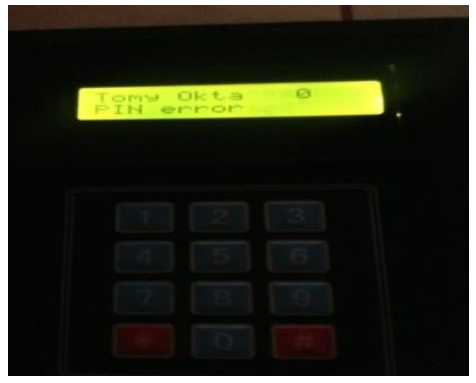

(c)

Gambar 11. (a) Pengujian Password Benar, (b) Pengujian Pengantian Password,

(c) Pengujian Password Salah

\subsection{Pengujian Sistem Alarm}

Pengujian ini dilakukan untuk menguji akurasi sensor kecepatan dan berfungsi tidaknya alarm. Pengujian dilakukan sebanyak 15 kali dengan jumlah putaran roda yang berbeda-beda pada saat motor dalam kondisi motor mati. Hasil pengujian bisa dilihat pada Tabel 1.

Tabel 1. Tabel Pengujian Sistem Alarm

\begin{tabular}{|r|l|r|l|}
\hline No & Sensor kecepatan & Jarak tempuh $(\mathrm{m})$ & Kondisi Alarm \\
\hline 1 & 1x putaran & 1.65 & Mati \\
\hline 2 & 2x putaran & 3.3 & Mati \\
\hline 3 & $3 x$ putaran & 4.95 & Mati \\
\hline 4 & $4 x$ putaran & 6.6 & Mati \\
\hline 5 & $5 x$ putaran & 8.25 & Mati \\
\hline 6 & 6x putaran & 9.9 & Mati \\
\hline 7 & $7 x$ putaran & 11.55 & Mati \\
\hline 8 & $8 x$ putaran & 13.2 & Mati \\
\hline 9 & $9 x$ putaran & 14.85 & Mati \\
\hline 10 & $10 x$ putaran & 16.5 & Mati \\
\hline 11 & $11 x$ putaran & 18.15 & Mati \\
\hline 12 & $12 x$ putaran & 19.8 & Mati \\
\hline 13 & $13 x$ putaran & 21.45 & Mati \\
\hline 14 & $14 x$ putaran & 23.1 & Mati \\
\hline 15 & $15 x$ putaran & 24.75 & Hidup \\
\hline
\end{tabular}

Hasil pengujian menunjukkan bahwa saat sensor kecepatan melebihi batas putaran yang telah ditentukan (lima belas kali putaran) tanpa memasukan password terlebih dahulu maka sistem keamanan akan aktif dan mengkunci semua sistem pada sepeda motor. Tulisan "System locked" akan muncul seperti pada gambar yang terlihat, alarm akan berbunyi dan sepeda motor akan mati secara otomatis. 


\subsection{Pengujian Sistem Speed Limiter}

Pada pengetesan sistem speed limiter, yang kita lakukan adalah memvalidasi perhitungan kecepatan kendaraan yang didapat dari alat (sensor kecepatan) dengan spedometer motor, memastikan sistem peringatan (alarm) telah bekerja, memastikan pemutusan arus (mematikan mesin) untuk menurunkan kecepatan sudah bekerja, serta memastikan fitur input batas kecepatan bisa berfungsi.

Rata-rata tingkat akurasi pada speedometer alat terhadap speedometer motor adalah 83,1\% dan hasil tingkat error pada alat adalah $16.9 \%$. Dari hasil pengujian dapat disimpulkan bahwa tingkat validasi speedometer alat cukup baik setelah dibandingkan dengan speedometer motor. Hasil pengukuran validasi kecepatan kendaraan bisa dilihat pada Tabel 2.

Tabel 2. Hasil Pengujian Validasi Spedometer

\begin{tabular}{|c|c|c|c|}
\hline Pengujian ke- & $\begin{array}{c}\text { Spedometer } \\
\text { Motor }\end{array}$ & $\begin{array}{c}\text { Spedometer } \\
\text { Alat }\end{array}$ & Tingkat Akurasi \\
\hline 1 & $10 \mathrm{~km} / \mathrm{h}$ & $8 \mathrm{~km} / \mathrm{h}$ & $80 \%$ \\
\hline 2 & $15 \mathrm{~km} / \mathrm{h}$ & $13 \mathrm{~km} / \mathrm{h}$ & $86 \%$ \\
\hline 3 & $20 \mathrm{~km} / \mathrm{h}$ & $17 \mathrm{~km} / \mathrm{h}$ & $85 \%$ \\
\hline 4 & $25 \mathrm{~km} / \mathrm{h}$ & $22 \mathrm{~km} / \mathrm{h}$ & $88 \%$ \\
\hline 5 & $30 \mathrm{~km} / \mathrm{h}$ & $25 \mathrm{~km} / \mathrm{h}$ & $83 \%$ \\
\hline 6 & $35 \mathrm{~km} / \mathrm{h}$ & $28 \mathrm{~km} / \mathrm{h}$ & $80 \%$ \\
\hline 7 & $40 \mathrm{~km} / \mathrm{h}$ & $33 \mathrm{~km} / \mathrm{h}$ & $82 \%$ \\
\hline 8 & $45 \mathrm{~km} / \mathrm{h}$ & $38 \mathrm{~km} / \mathrm{h}$ & $84 \%$ \\
\hline 9 & $50 \mathrm{~km} / \mathrm{h}$ & $41 \mathrm{~km} / \mathrm{h}$ & $82 \%$ \\
\hline 10 & $55 \mathrm{~km} / \mathrm{h}$ & $45 \mathrm{~km} / \mathrm{h}$ & $81 \%$ \\
\hline
\end{tabular}

Sedangkan hasil pengujian sistem speed limiter yang lainnya bisa dilihat pada Tabel 3. Berdasarkan hasil pengujian, dapat disimpulkan alat telah bekerja sesuai fungsi yang telah dirancang, dimana jika kecepatan sepeda motor melebihi batas standar kecepatan yang ditentukan maka alarm akan aktif dan jika dalam 15 detik kecepatan kendaraan tidak turun dibawah batas kecepatan maka sistem akan mematikan mesin sepeda motor.

Tabel 3. Hasil Pengujian sistem Speed Limiter

\begin{tabular}{|c|c|c|c|c|}
\hline Pengujian ke- & Kecepatan & Batas kecepatan & Alarm & $\begin{array}{c}\text { Mesin Motor (setelah } \\
\text { 15 detik) }\end{array}$ \\
\hline 1 & $78 \mathrm{~km} / \mathrm{h}$ & $50 \mathrm{~km} / \mathrm{h}$ & Aktif & Stop engine \\
\hline 2 & $69 \mathrm{~km} / \mathrm{h}$ & $50 \mathrm{~km} / \mathrm{h}$ & Aktif & Stop engine \\
\hline 3 & $70 \mathrm{~km} / \mathrm{h}$ & $50 \mathrm{~km} / \mathrm{h}$ & Aktif & Stop engine \\
\hline 4 & $61 \mathrm{~km} / \mathrm{h}$ & $50 \mathrm{~km} / \mathrm{h}$ & Aktif & Stop engine \\
\hline 5 & $59 \mathrm{~km} / \mathrm{h}$ & $50 \mathrm{~km} / \mathrm{h}$ & Aktif & Stop engine \\
\hline
\end{tabular}

\section{Kesimpulan}

Suatu alat sistem keamanan yang khusus dirancang untuk sepeda motor telah dirancang, diimplementasikan, dan diuji. Hasil pengujian menunjukkan seluruh fitur-fitur seperti kunci keamanan, sistem alarm, dan sistem speed limiter telah berfungsi dengan baik. Keberadaan alat ini diharapkan bisa menjadi salah satu alternatif untuk menekan tingkat kriminalitas pencurian sepeda motor serta dapat mengurangi tingkat kecelakaan lalu lintas yang melibatkan sepedamotor terutama yang disebabkan karena kecepatan sepeda motor yang terlalu tinggi. 


\section{Daftar Pustaka}

[1] Bagenda Dadan Nurdin, Prasetya Indra. 2014. Prototipe Sistem Keamanan Dan Pengendalian Sepeda Motor Berbasis Mikrokontroler Atmega8535 . JURNAL LPKIA, Vol.1 No.1, September 2014

[2] Carlos. ARDUINO UNO. Available : http://arduino.cc/en/Main/arduinoBoardUno. [Accessed 24 Agustus 2013]

[3] Kecelakaan Lalu Lintas Menjadi Pembunuh Terbesar Ketiga Available : http://www.bin.go.id/awas/detil/197/4/21/03/2013/kecelakaan-lalu-lintas-menjadi pembunuh-terbesar-ketiga [Accessed 20 June 2015]

[4] Kurniawan Mochamad Teguh, Rizal Achmad. Rancang Bangun Sistem Pengaman Sepeda Motor Anti Maling. Prosiding SENTIA 2009 - Politeknik Negeri Malang

[5] LCD Liquid Cristal Display Available : http://elektronika-dasar.web.id/teorielektronika/lcd-liquid-cristal-display/ [Accessed 7 Desember 2014]

[6] Produk 238 Reed Switch Available : http://indo-ware.com/produk-238-reed-switch.html [Accessed 24 Agustus 2013]

[7] Saleh Robby, Ping Ho, S. Achmad, U. Aulia. Sistem Keamanan Motor Menggunakan Telepon Selular Berbasiskan Komunikasi Dua Arah. CommIT, Vol. 1 No. 1 Mei 2007, hlm. 1-9

[8] Teknik Membaca Keypad dengan Microcontroller available :http://inkubatorteknologi.com/2-teknikmembaca-keypad-dengan-microcontroller.[Accessed 6 Agustus 2014] 